\section{Critical Notice of Morals, Reason, and Animals}

\author{
James Lindemann Nelson \\ Center for Ethics and Humanities in the \\ Life Sciences \\ Michigan State University
}

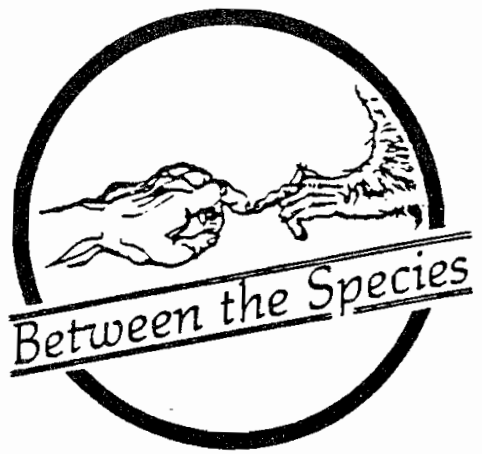

philosophy is (in)famous, the combined force of their work has been to put apologists for theory's traditional pretensions somewhat on the defensive. The critics' positive views about the form of moral philosophy sans moral theory, have, however, been even more varied (and rather vaguer) than their critiques. From the lack of an articulate positive program, along with suspicions that antitheory in ethics might have strongly conservative implications, the theorists have taken heart.

Sapontzis' contribution to this debate-although he modestly does not identify it as such-is quite important. He provides an object lesson in how to do moral philosophy without a commitment to a single unified theory which demonstrates in the abstract what "makes right acts right." In so doing, he shows that it doesn't take such a theory to provide an intellectually respectable critique of a major social institution. known work of Singer and Regan. Morals, Reason, and Animals assembles and refines the themes introduced in his earlier essays. The result is an interesting contribution to a discussion in contemporary moral theory, as well as an examination of our dealings with nonhumans that shows just how thoroughly dubious they are.

A major ongoing debate in moral philosophy concerns what, to use a characteristically Sapontzian way of putting things, might be called the (in)Significance of Moral Theory. Influential writers such as Bernard Williams, Annette Baier, Martha Nussbaum, and Alasdair MacIntyre, among many others, have all raised considerable doubts about the philosophical enterprise of "grounding" ethics in moral theory, especially if that is taken to mean one which claims to be able to derive our moral duties from a small number of basic principles. ${ }^{1}$ Although the critics' reasons for inveighing against the "standard" conception of ethical theory exhibit the variety for which
REVIEW

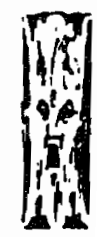


Nonhumans cannot engage in moral theory, nor, often, in the kinds of activities which moral theorists claim to be crucial for moral standing (which are many times almost identical with those needed to build a theory). But careful attention to what Sapontzis calls "everyday morality" shows that envisaging kingdoms of ends, or universalizing the maxims of our actions, or being strictly impartial, are not needed in order to behave well, nor to merit the respectful concern of others.

Accordingly, when Sapontzis sees a conflict between philosophical accounts of ethics, and common moral thinking and behavior, the philosophical accounts are shown the door. For example, if Kant holds that the only actions which have true moral value are those which proceed out of a respect for the moral law, Sapontzis will note that we more greatly prize the parent who acts in behalf of her children out of love than the parent who acts out of duty alone; if Singer claims that taking a moral point of view demands that we be prepared to defend our judgements and behavior with impartial reasons, Sapontzis counters with examples of people who may lack what William Ruddick has called "discursive moral competence," but who we would all admit are capable of acting morally. ${ }^{2}$

Sapontzis unfolds this general theme in two ways. He argues that attempts to rule animals out of the sphere of moral considerability are speciously philosophical in that they, for example, pitch the standard of rationality supposedly required for moral standing so high as to leave many humans out in the cold. The other tactic is to show that the moral aims that commonly nun through our community would all be better served by a policy of liberating animals than they would by continuing the status quo.

The first strategy occupies the beginning of the book, where he concentrates on showing the limits of reason's importance for moral staus. A particularly significant claim here is that nonhuman animals can act in ways that have a moral value that reflects on the actor. Sapontzis calls this "agent dependent" moral value, or moral $_{a d}$ value. This is a bold idea. It pulls nonhumans into the moral community not simply as "moral patients," but as moral agents as well, and in so doing, questions common ideas about the gulf separating humans and nonhumans that are unchallenged even by prominent proponents of animals. Many nonhumans, Sapontzis says, meet all the reasonable criteria for acting in moral ${ }_{a d}$ ways: they act freely and straightforwardly in response to the goods and evils a situation presents to them. He does admit that nonhumans lack the interest and ability to strive to make the world a better place; hence, they are not fully moral agents. But, like "kindhearted, spontancously generous [and] compassionate people" (p. 45), they are virtuous agents, and hence their acts possess moral ${ }_{a d}$ value.

This may strike even friends of animals as a bit extreme; they may recall Aristotle's distinction between "natural virtue," which is the portion of children and animals, and "virtue in the full sense of the word," which requires (normal human) intelligence (cf. Nichomachean Ethics VI.13). For example, John McDowell, who accepts this distinction, has recently contrasted the virtue of a genuinely kind person with "the outcome of a blind, non-rational habit or instinct, like the courageous behavior - so called only by courtesy-of a lioness defending her cubs."3 But Sapontzis is skillful at disarming such doubts. He points out that there is a vast difference between highly routinized, blindly instinctual behavior, such as the spawning instinct of salmon, and the much more flexible, context-sensitive actions of such social animals as wolves, who exhibit faithful and affectionate behavior as spouses and parents, and are, in words borrowed from Mary Midgley, "paragons of steadiness and good conduct" (p. 27).

Narrowing the perceived moral gap between nonhumans and humans is a significant result, especially when coupled with Sapontzis' critique of the concept of 'personhood.' Philosophers often take the conditions for inclusion in the set of persons to be identical with those necessary and sufficient for having a right to life. Some claim that the concept of a person includes many but not all human beings (fetuses, infants, and the permanently and profoundly retarded are the usual exceptions) and some nonhumans (primates, cetaceans and perhaps others as well). Personhood may thus appear to be an ethically progressive concept, as it is nonspeciesist, and significantly expands the sphere of rights holders. But, as Sapontzis sees it, despite its advances over previously popular moral notions, personhood still retains "the logic of prejudice." The upshot of his discussion is that basing moral status on what he calls "metaphysical" characteristics of a thing (i.e., what basic ontological category it occupies, of which personhood may be an example) is as morally arbitrary as basing moral status on considerations such as race or gender. The only defensible grounds for assigning or withholding moral status is the character 
of the being in question ("or other evaluative considerations, such as minimizing suffering, relevant to making the world a morally better place." (p. 64)), and this is where the significance of animal virtue comes in. Animals merit our moral respect, not because they may be persons, and not (solely) because they are sentient, or subjects of a life, but because they are generally decent, sometimes admirable, occasionally heroic beings.

The book's second part clarifies and motivates the animal liberation movement. The most effective way of examining a moral position, as Sapontzis sees it, is to note its relationship to the three chief themes that run through everyday morality - briefly, these are promoting virtue, making the world a happier place, and fairness. This technique threatens to break down if some themes supported a proposed practice, while others run counter to it Happily_although perhaps surprisingly, given our actions-all three elements of common morality speak for, rather than against, the liberation of animals.

One such element is concern for moral character, for the development of "compassion, altruism, respect for the interests and rights of others, a sense of faimess, a willingness to stand up and take risks for those who cannot defend themselves, and so forth" (p. 90). Animal liberation contributes to this goal primarily by extending the sphere of moral considerability. There is simply much more that a conscientious moral agent now has to keep in mind. The lines that divide the world into the issues that require moral reflection and virtue (e.g., our duties to the homeless, abortion) and those that are morally discretionary (what to eat for lunch, what experiments to perform in pursuit of one's $P h . D$.) will no longer be arbitrarily drawn. At the same time, the extra challenges imparted by liberating animals are realistic, not utopian, requiring moral seriousness, but not sainthood. Liberating animals, although making morality a more complex and more pervasive part of our lives, would not overburden us; that is not what morality is for. It would make of us a more compassionate, more morally imaginative and creative community, which fits in squarely with our own best ideals.

But this line can at best lend ancillary support to a position established on other grounds. One important moral virtue is discernment, which involves recognizing which issues appropriately make moral demands on us and which do not; the corresponding vice is overscrupulousness. Whether it is a good thing to make the part of our lives that involves nonhumans more or less morally complex is not a matter that can be reasonably influenced by noting that, were we to think of them as more morally significant, we'd have to make more and more difficult ethical decisions; the same could be said in support of a proposal to extend moral recognition to used cars. The crux of the matter is whether doing so involves proper discernment or overscrupulousness. What Sapontzis may be illustrating here is that the various threads of common morality interpenetrate and reinforce one another, and that each borrows from the other in showing where practical reason should lead us.

A line more directly supported by our concen for moral character returns to the argument that animals can be virtuous agents, and suggests that there is a certain incoherency in professing great moral respect for virtue, but none for those who are virtuous. What is the sense in admiring the deed and kicking the doer? This argument appears here and there in Sapontzis' book, but oddly enough it is not worked out in much detail in the section that explores how respect for virtue motivates animal liberation.

Another part of the common morality is the goal of making the world a happier place. Although the point has been disputed, it seems very likely that a policy of reducing and ultimately ending the vast suffering that nonhumans undergo at our hands would substantially enhance the balance of satisfied to frustrated interests in the world, and thus contribute to this goal. It is true that such a shift would cause personal and systematic dislocations for humans, but these, as Sapontzis points out, would be eased by the development of alternatives to animal-consuming industries, and by the fact that the shifts would occur over an extended period of time (although, presumably, this time lag in implementing radical reforms is something to be regretted, not welcomed, by serious animal advocates). But the fundamental point is that the stresses occasioned by the change would fade with time, but the benefits enjoyed by animals would continue indefinitely into the future. This consideration, of course, presupposes a certain scope to everyday morality's concern with a better world, namely, that it extends into the indefinite future. It is worth noting that not even every version of utilitarianism does that. As Sapontzis himself thinks that our concern with the future ought not to extend more than seventy-five or a hundred years hence-a 
point to be examined later-there seems an internal tension here, too.

Yet another tension might arise from another difference between everyday morality's interest in making the world a better, happier place, and that of utilitarianism, the philosophical theory built on this theme. The theory bids us to be strictly impartial in our assessment of interest satisfaction and frustration, but ordinary morality has no such requirement, and, in fact, directs us to give special regard to our kin and friends. Yet the magnitude of animal suffering, and the relative triviality of the human interests which can only be served by that suffering, must trump even a moral perspective which gives special regard to the interests of our nearest and dearest, unless that view is simply a rationalization for personal chauvinism of the most extreme kind, and not a concern that the world be a better place at all. The only plausible exception to this is the case of the best animal-based medical research. Research that is of high quality from both scientific and humane standpoints, which targets debilitating and widespread diseases, and from which there is good hope of progress, may perhaps be justified both from a utilitarian standpoint and from the standpoint of this aspect of common morality. It is true that morality's other features-the development of virtue and fairness-might speak against rersearch. In that case, however, we would be in a situation of internal moral conflict, and Sapontzis' work, resting on the convergence of all elements of ordinary morality on a broad animal liberation platform, does not contain strategies for resolving such conflict.

The final aspect of common morality is fairness. Certainly in research, as in other aspects of our interactions with them, animals typically bear all the burdens while humans reap the benefits. Intuitively, this seems unfair, a charge that could only be turned away by considering reasons why animals simply don't count from the perspective of faimess, or why, despite appearances, they aren't really being treated unfairly. Sapontzis handles the first of these responses perhaps too briefly, simply noting that to say that an animal is being treated unfairly is not to make a category mistake. But even if the claim isn't patent nonsense, it might still be disguised nonsense. Some philosophers, for example, have thought that considerations of justice arise only among creatures that are roughly equivalent in their vulnerabilities to one another, a condition that does not hold between humans and nonhumans. ${ }^{4}$ Yet it does seem intuitively correct to say that humans who don't satisfy the so-called "circumstances of justice"say, the weak and infirm - can still be treated unfairly, and if they can, why not animals of roughly equivalent powers and vulnerabilities? This strategy smacks of the "argument from marginal cases," an appeal which Sapontzis finds weaker than many animal advocates, as he seems to admit that our care for "marginal" members of our own species may be urged by sentiment, rather than dictated by principle (see pp. 141ff). If so, then our tenderness to the weak of our own specieseven if that tenderness is expressed by a sense that it is not fair for the strong to exploit the weak-may not be good grounds for claiming that nonhumans are appropriate subjects of justice. The more effective strategy is probably to point out, as Sapontzis does, that it seems part of the point of morality-in particular of the part that concerns fairness-to defend the weak against exploitation by the strong, and that any account of justice that overlooks that is incomplete.

If there is no categorical reason for denying that animals can be treated unjustly, then defenses of the fairness of their treatment are generally quite lame, although Sapontzis has the patience to show just why they limp. There is, however, a set of considerations, the "replacement argument," which may be of some serious interest. It contends that it is pemissable to use and kill an animal if its existence depends upon its being used and killed by us, and if after death, it will be replaced by another animal, which would not have existed were the first animal to remain alive, and if both animals have lives roughly equally worth living.

Sapontzis spends an entire chapter unpacking this argument. He first notes that it is a response to an idealized case. The animals stocked in our factory farms and our laboratories are of such moral interest precisely because they fail to have lives worth living. Still, one can imagine reforms of animal research, if not intensive farming, which might greatly enhance the lives of its purpose-bred subjects. Suppose, for example, that animals bred for research were housed in settings that allowed them to enjoy a good deal of what life might hold for them, were used only in crucial research, and were painlessly euthanized. If the replacement argument were sound, it would seem to justify this possibility as a goal for the reform of animal research.

Whether anyone's life is replaceable depends on what makes a life valuable. Sapontzis displays a number of competing accounts, which fall into utilitarian and 
nonutilitarian families. The nonutilitarian accounts are divided in their tum: one version sees our lives as the very source of moral value, due to our capacity for autonomous action; the other rests our significance on the more basic capacity simply to confer any kind of value on things.

On Sapontzis' view, neither of these accounts will support the replacement argument. On the first, the decent exercise of their moral agency earns animals the right to live out their lives. On the second, agents typically value their own pursuit of their own projects; replacement by someone else - even if she has equally worthy projects-does not preserve that. This, of course, would seem to assume that animals not only have an interest in living so as to complete their projects, but that they take an interest in living as well. That nonhumans typically can do so is doubtful. Nor is it clear that valuing our own projects protects us from replacement; surely, our replacements will value their own projects as well, so it isn't clear what's irretrievably lost.

Utilitarianism would, at any rate, seem to be the more natural setting for the replacement argument, as it is less hospitable to the idea that individuals-as opposed to the experiences they "contain"-have intrinsic moral worth. But Sapontzis argues that a general utilitarian outlook will yield several relevant accounts of the value of life, that only one of them clearly supports the replacement argument, and that the considerations often urged in behalf of that particular view are much less persuasive than they at first appear.

Utilitarianism consists of both a theory of the good (classically, hedonism; more currently, the view that the satisfaction of interests is intrinsically good) and a range principle, which determines for whom the good or bad consequences of a given action or policy are to be considered. The crucial distinction for Sapontzis' discussion is between "total population" and "prior existence" versions of the range principle. "Total population" utilitarianism bids us to maximize the overall good taking into account both currently existing sentient beings, as well as those who may come to exist; it is distinguished from the "prior existence" version which restricts itself to sentient beings once they have begun to exist as such. Clearly, the "prior existence" versions will protect animals against the prospect of replacement, but total population versions of utilitarianism (depending on which theory of the good they employ) leave us more or less vulnerable to the prospect of replacement.
A significant weakness of prior existence utilitarianism seems its conflict with the idea that future generations have a moral claim on us. Sapontzis' discussion of this problem is not convincing. He points out that, even on the prior existence view, we have duties to the future which extend between seventyfive and one hundred years hence, since there are now people living who will still be alive then, and, as previously mentioned, he thinks that's long enough. But this seems very dubious in the light of such moral questions as arise from the production and storage of nuclear waste, which presents dangers which extend thousands of years into the future, and whose management seems much more problematic as we wonder about the reliability of storage technology not a century, but rather a millenium ahead.

The discussion of the replacement argument occupies a central position in the book's third part, which also features insightful discussions of whether animals have interests (targeting primarily R. G. Frey, who has maintained that only language-users have interests) and whether death is a harm to nonhumans. In both instances, Sapontzis maintains that it is not to the point whether a creature can cognitively entertain a certain proposition-for example, that death is an ill. It is sufficient that the creatures have feelings of welland ill-being. Artifacts and plants fail to have morally considerable interests precisely because they lack this capacity to feel. Since death precludes the further satisfaction of those interests, it is (prima facie, at least) a harm to any interest bearer.

In the final part of the book, Sapontzis works out some practical implications of the kind of animal liberation he supports. Once again, his views are characterized by their originality, clarity, and cogency. His topics include the obligation to be vegetarian, the legitimacy (or otherwise) of animal research, how we should respond to the fact that animals prey on other animals, and the relationship of his position to environmental ethics. All of these discussions repay attention, but the focus here will be on his remarks concerning animal research.

Sapontzis argues that nonhumans should not be exposed to greater research risks than humans. This would not rule out animal research altogether: as he sees it, animals can give a meaningful kind of consent to participation in some research (typically, research that is noninvasive, and which offers them some reward for participation) and others can appropriately consent 
for them, so long as the research is innocuous, or in the animal's own best interests. Actually, if equivalence to human levels of protection is the touchstone, then the net gets cast a bit wider than he suggests: well children are legally allowed to be subjects of experiments which place them at minimal risk and some discomfort, even if the experiments are not in their own interests; children who are in terminal conditions may become part of "Phase One" drug tests, which are of no therapeutic benefit and which may add substantially to their discomfor: ${ }^{5}$

Whatever the precise dimensions of allowable experimentation, it seems clear that reforming scientific research to conform with them would involve very big changes. But animal research apologists might claim that even on Sapontzis' account, there is a moral difference between typical humans and nonhumans: we are fully moral agents, capable of striving to make the world a better place, while animals can act virtuously in ways largely limited to the confines of the world as it is presented to them.

There are other, more or less reasonable attempts to make sense of the claim of human moral superiority: our capacity for both enjoyment and suffering might be greater than those of animals, for example. But, as Sapontzis shows, none of this clearly demonstrates human superiority. Unlike animals, we may have the capacity to strive to make the world better, but what's actually been our track record? This argument is weakened by the very suffering which it attempts to justify. As for our allegedly greater degrees of suffering and enjoyment, these cut both ways: there is a wealth of sensations closed to humans but possessed by different animals in varying degrees, and an animal's restricted grasp of the past and future might make suffering harder to bear in some ways, if easier in others.

But even if there were ways in which humans could be shown to be morally superior to animals, we're still left with the issue of what behavior that superiority would license. Aл interesting feature of Sapontzis' investigation of this point is his emphasis on the egalitarian character of utilitarianism. He notes the antipathy to aristocracy which has traditionally been a part of utilitarian thought, and points out that the theory is structurally committed to regarding each individual equally in determining the harm/benefit consequences of a particular activity. Hence it would not support even the idea of moral superiority. There is, however, some controversy over whether utilitarianism's egalitarianism plays the role of a theory of distributive justice. D. D. Raphael, for one, claims that it does, but admits that this is a matter even utilitarians are confused about; Tom Regan, on the other hand, interprets the Benthamite notion that "each should count for one and no one for more than one" as solely a predistributive kind of egalitarianism, in principle compatible with hierarchical distributions of utilities, so long as such distributions result in an utility sum that is optimal considered overall. ${ }^{6}$ No doubt, Bentham and others thought that utilitarianism would have antiheirarchical implications, but that was because they took hierarchies to have bad consequences considered generally and impartially, not because they had a special independent objection to the notion.

If Regan is right, standard forms of utilitarianism as such do not undermine the moral hierarchy presupposed in even high quality animal research; rather, such research may be a practical instance of the conflict between justice and utility that utilitarianism is so often seen as giving rise to in theory.

Since the ethical perspective of Morals, Reason, and Animals is pluralistic, resolving this disagreement about the implications of utilitarianism is not crucial. What is more significant is that Sapontzis' account of animal research succeeds in raising significant issues that have been underexplored in what has become a huge literature. It does, however, leave unexamined the neglected yet natural question of what is our duty with respect to the benefits we derive from animal research. In other words, how close is the analogy between our duty to stop profiting from the exploitation of animals in factory farms by becoming vegetarianswhich Sapontzis spends a chapter supporting-and a duty to stop profiting from the exploitation of animals in medical research labs-which Sapontzis doesn't mention?

Becoming a vegetarian has virtually no negative impact on key interests, as nutritious and tasty substitutes are available. Boycotting medicine is not so easy. As animal experimentation infects the whole of medicine, refusal to profit from it is tantamount to refusal to profit from the medical system as a whole. It is one thing to ask a meat-eater to give up her Big Mac. It is quite another to ask an AIDS sufferer to give up his AZT.

But if this difference in the character of affected interests allows one to accept the benefits of animal research, why does it not distinguish the moral 
acceptability of the whole enterprise over that of factory farming? In other words, many of us currently, and all of us potentially, owe our lives to medical interventions, and owe the availability of most of those interventions to animal research. Can we consistently reap the benefits of research, and yet demand that it be stopped cold (as opposed to greatly reformed) before reasonable alternatives are discovered? Might that not be asking us to ascribe to an ethic for saints and heroes, rather than for common folks adhering to everyday morality? The question deserves more attention than it gets.

In the preface to Morals, Reason, and Animals, Sapontzis anticipates that people will come to his book wondering why, after the work of Singer, Regan, Rollin, Clark, Midgeley and others, anything more can usefully be said about the philosophical foundations of animal liberation. What Sapontzis achieves is not only to give us a new philosophical perspective on animals - most notably, his notion that they are virtuous agents, rather than merely subjects of moral concernbut a new view of what it is to give a philosophical foundation to an ethical movement. He calls his book a "second generation" contribution to the philosophical debate on the ethics of interspecies relationships; if it sets the tone for discussion in this generation, the implications for both practice and theory are rich.

\section{Notes}

1 A useful collection of essays on this topic is Stanley G. Clarke and Evan Simpson, eds., Anti-Theory in Ethics and Moral Conservatism (Albany: State University of New York Press, 1989).

2 See Peter Singer, Practical Ethics (Cambridge: Cambridge University Press, 1979), pp. 9-10, referred to in Sapontzis, p. 22.

3 John McDowell, "Virtue and Reason" in Clarke and Simpson, p. 88. Contrast his account with the very effective example of nonhuman virtue given in James Rachels' "Do Animals Have a Right to Liberty?" in Tom Regan and Peter Singer, eds., Animal Rights and Human Obligations (Englewood Cliffs, NJ: PrenticeHall, 1976). Several primates were forced to observe that their food-gathering activities caused conspecifics painful electric shocks. More than half the animals went hungry rather than subject their fellows to the pain; animals who had previously been shocked were especially willing to forego eating.

4 See, for example, John Rawls' discussion of the "circumstances of justice" in A Theory of Justice (Cambridge: Harvard University Press, 1971), pp. 127ff.

5 Department of Health and Human Services guidelines pertaining to experimentation on children are discussed in Baruch Brody and Tristram Englehardt, eds., Bioethics: Readings and Cases (Englewood Cliffs, NJ: Prentice-Hall, 1987), pp. 266-267.

6 For Raphael's discussion, see Chapter 5 of his Moral Philosophy (Oxford: Oxford University Press, 1980). For Regan, see The Case for Animal Rights (Berkeley and Los Angeles: University of California Press, 1983), chapters 6 and 7.

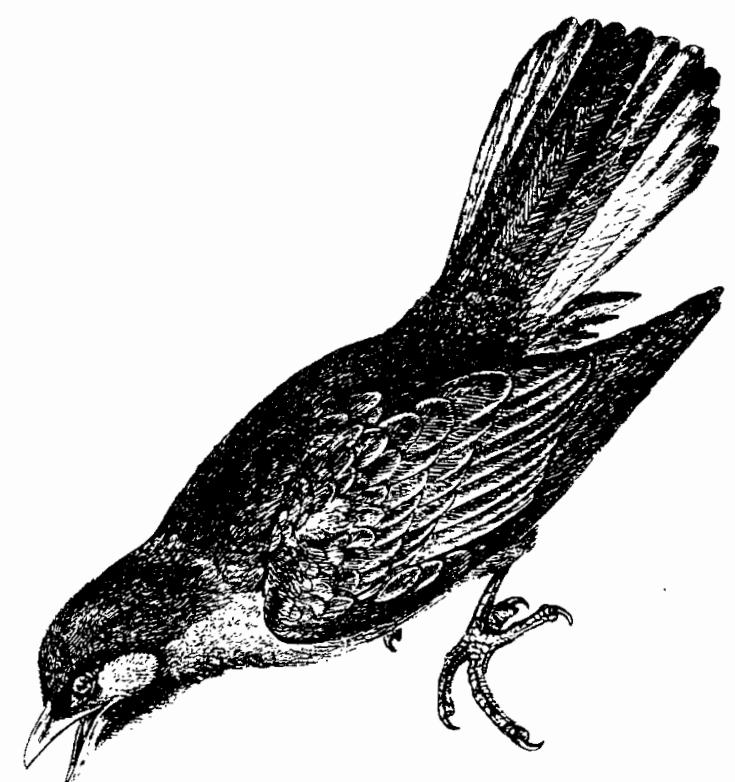

